\title{
Critical Care and Emergency Medicine
}

Open Access

RESEARCH ARTICLE

\section{Incidence of Venous Thromboembolism in Asian Trauma Patients - An Asian Trauma Centre Review}

\author{
Wee Ming Tay*, TS Go and LT Teo \\ Department of General Surgery, Tan Tock Seng Hospital, Singapore
}

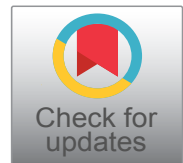

*Corresponding author: Wee Ming Tay, Surgical Resident, Department of General Surgery, Tan Tock Seng Hospital, 11 Jalan Tan Tock Seng, 308433, Singapore, Tel: +65-91187658

\begin{abstract}
Objective: To evaluate the incidence of venous thromboembolism (VTE) in Asian trauma patients and the relation to use of chemoprophylaxis with low molecular weight heparin $(\mathrm{LMWH})$.

Methods: The Tan Tock Seng trauma database between December 2011 and December 2012 was reviewed. All trauma patients with an injury severity score of 9 or more were included. All medical records were screened for Duplex ultrasound (US) of lower limbs, any computed tomography pulmonary angiogram (CTPA) performed and whether there was use of LMWH chemoprophylaxis. Patients hospitalized for less than 2 days were excluded.

Results: From December 2011 to December 2012 there were 1028 patients who fit our inclusion criteria. Of these patients, $33(3.2 \%)$ received LMWH. All patients received mechanical prophylaxis in the form of pneumatic calf compressors. A total of 5 patients had VTE events. The incidence of VTE was $0.5 \%$ in the whole group and $0.8 \%$ in those with lower limb or pelvic fractures.

Conclusion: The incidence of VTE in Asian trauma patients is low compared to the west despite the low incidence of LMWH chemoprophylaxis. Mechanical prophylaxis appears to be sufficient in the prevention of VTE.
\end{abstract}

\section{Introduction}

Severely injured trauma patients are known to have high rates of venous thromboembolism (VTE) due to the frequent need for surgical interventions, prolonged length of stay, the nature of their injuries and the consequent immobility $[1,2]$. As such, many guidelines recommend the use of routine chemoprophylaxis for trauma patients [3].
It is widely believed that the incidence of DVT in Asian patients is low compared to the Caucasians $[4,5]$. The truth of this is disputed as some studies have quoted postoperative DVT rates of $17-58 \%$, which is comparable to the Western populations [6]. On the other hand, other studies have quoted a much lower incidence of less than 2\% [7]. In fact, a survey of Asian institutions revealed that many do not practice routine low molecular weight heparin (LMWH) chemoprophylaxis [8].

Interestingly, little exists in the literature on the incidence of VTE in Asian trauma patients. The aim of this study was to therefore determine the incidence of VTE in patients admitted for moderate to severe trauma.

\section{Methods}

Information was retrieved from the trauma database for all patients admitted for trauma injuries from December 2011 to December 2012 at Tan Tock Seng Hospital, a major trauma centre in Singapore. The collection of patient information for this database has been approved by the ethics committee.

Inpatient medical records were reviewed and demographic, clinical and surgical information were extracted. Specifically, the mechanism, extent and type of trauma injury, the use of mechanical or chemoprophylaxis and the incidence of VTE events and their treatments were recorded.

Only patients with an Injury Severity Score (ISS) of $\geq$ 9 were studied. Patients who died or were discharged

Citation: Tay WM, Go TS, Teo LT (2018) Incidence of Venous Thromboembolism in Asian Trauma Patients - An Asian Trauma Centre Review. Int J Crit Care Emerg Med 4:057. doi.org/10.23937/24743674/1510057

Accepted: November 22, 2018: Published: November 24, 2018

Copyright: (C) 2018 Tay WM, et al. This is an open-access article distributed under the terms of the Creative Commons Attribution License, which permits unrestricted use, distribution, and reproduction in any medium, provided the original author and source are credited. 
within 2 days of admission were excluded. There were no patients younger than 14 years as the hospital only serves an adult population.

Routine screening for DVT was not performed and hence the diagnoses of VTE were based upon clinical suspicion only. Lower limb duplex ultrasonography and computed tomography pulmonary angiograms (CTPA) were used to diagnose DVT and pulmonary embolus (PE) respectively. The diagnosis of VTE during inpatient stay or within 30 days of admission was recorded. Clinically significant DVTs were regarded as those which were symptomatic or above knee. These and PEs were treated with therapeutic anticoagulation. The hospital record for each patient was also screened for readmissions and/or any mortality within 30 days.

Routine chemoprophylaxis was not given to all admitted trauma patients. Patients thought to be of high risk, such as the presence of a past history of VTE or known thrombophilia were commenced on LMWH at the attending clinician's discretion. Mechanical forms of DVT prophylaxis were instituted for all patients and this included early mobilization, the use of thromboembolic (TED) stockings and physiotherapy. Sequential Compression Devices (SCD) were also used intraoperatively and in selected immobilized patients.

Descriptive statistics were used, with mean and standard deviation (SD) for variables with a normal distribution and median and range for variables with a skewed distribution.

\section{Results}

During the study period, a total of 1155 patients with an ISS $\geq 9$ were admitted. Of these, 127 patients were excluded due to early death or discharge. The remaining 1028 patients formed the basis of this study.

The characteristics of these patients are summarized in Table 1 . Briefly, $58 \%$ of patients were male and the mean age was 59 years. The ethnicity distribution approximated that of the Singaporean population. The median ISS was 10.

The vast majority of patients suffered from blunt trauma (98\%). 369 (36\%) patients suffered lower limb and/or pelvic injuries. The median length of stay in hospital was 6 days. Only 33 patients (3.2\%) were given LMWH prophylaxis.

A total of five patients had VTE events giving an incidence rate of $0.5 \%$. Three had DVTs, one had PE with no evidence of DVT and one had DVT together with PE. Although the VTE patients are so few precluding meaningful statistical analysis, this group of patients appeared older and were more likely to be female. They also were more severely injured with a median ISS of 12 (range 9-18). Interestingly though, only a single patient of this group had multisystem trauma. Three of these patients had lower limb fractures (femoral fracture), one with a subdural haemorrhage and the patient with multisystem trauma had multiple facial, thoracic vertebral and upper limb fractures.

None of these VTE patients had LMWH prophylaxis. The VTE episodes were diagnosed between 3 to 17 days of admission and the patient with VTE was hospitalized longer with a median of 13 days. The patients with VTE were treated initially with enoxaparin before being converted to warfarin. None of these patients developed complications from the anticoagulation treatment. All were subsequently discharged after treatment.

The overall incidence of VTE was therefore $0.5 \%$ ( 5 of 1028) and the incidence of VTE in patients with lower $\mathrm{limb} /$ pelvic fractures was $0.8 \%$ (3 of 369).

\section{Discussion}

Trauma patients are at high risk of mortality and morbidity from VTE [1,2]. Prolonged rest and hypercoagulability place these patients at high risk of thrombus formation.

Current guidelines are formulated based on Caucasian studies and recommend the routine use of LMWH in all high-risk trauma patients. The American College of Chest Physicians (ACCP) guidelines recommend the use of LMWH for major trauma patients as soon as it is considered safe to do so [3]. EAST guidelines also recommend that patients with pelvic fractures, complex lower extremity fractures, spinal cord injury or those with ISS $>9$ should receive LMWH chemoprophylaxis [9]. Risk factors often cited are: Lower extremity or pelvic fractu-

Table 1: Characteristics of patient population.

\begin{tabular}{|c|c|c|}
\hline & All patients & $\begin{array}{l}\text { Patients } \\
\text { with VTE }\end{array}$ \\
\hline & $n(\%)$ & $n(\%)$ \\
\hline \multicolumn{3}{|l|}{ Demographic characteristics } \\
\hline Age in years - mean (SD) & 59 & 79 \\
\hline Males & $593(58)$ & $1(20)$ \\
\hline \multicolumn{3}{|l|}{ Ethnicity } \\
\hline - Chinese & $769(75)$ & $3(60)$ \\
\hline - Indian & $103(10)$ & $1(20)$ \\
\hline - Malay & $98(10)$ & $1(20)$ \\
\hline - Other Asians & $58(6)$ & $0(0)$ \\
\hline \multicolumn{3}{|l|}{ Injury characteristics } \\
\hline \multicolumn{3}{|l|}{ Mechanism } \\
\hline - Blunt trauma & $1002(98)$ & $5(100)$ \\
\hline - Penetrating & $26(2)$ & $0(0)$ \\
\hline \multicolumn{3}{|l|}{ Injuries (selected) } \\
\hline - Lower limb fractures & $301(29)$ & $3(60)$ \\
\hline $\begin{array}{l}\text { - Knee and above knee } \\
\text { fracture }\end{array}$ & 251 & 3 \\
\hline - Isolated below knee fracture & 50 & 0 \\
\hline - Pelvic fractures & $72(7)$ & $0(0)$ \\
\hline - ISS Score - Median (Range) & $10(9-75)$ & $12(10-43)$ \\
\hline \multicolumn{3}{|l|}{ VTE and admission details } \\
\hline Chemoprophylaxis (LMWH) & $33(3.2)$ & $0(0)$ \\
\hline LOS in days - median & 6 & 13 \\
\hline
\end{tabular}


res, increased age, spinal cord or brain injury, high ISS score and prolonged immobilization.

Early studies before the widespread use of routine VTE prophylaxis have suggested that the risk of VTE may be as high as $59 \%$ in untreated patients and $28 \%$ despite prophylaxis $[10,11]$. Modern studies on VTE rates without prophylaxis are lacking due to the widespread use of thromboprophylaxis. However, a recent study which examined the VTE rates in 8216 patients from the National Surgical Quality Improvement Program (NSQIP) database suggest that with prophylaxis the rate of VTE is $1.4 \%$ [12]. Based upon this incidence, the latest ACCP guidelines have "worked backwards" and concluded the baseline risk in high risk surgical patients is only in the order of $6 \%$ [13]. The incidence of PE in absence of VTE prophylaxis is quoted as $3 \%$ in other trauma studies [1]. Whilst these rates suggest that the true incidence may be lower than previously thought, nonetheless, DVT is an important preventable complication which is associated with increased length of stay, ICU stay and pulmonary embolism [14].

The incidence of VTE in the Asian population is still subject to much debate. Some publications have suggested that the rates of VTE are similar to that of the West and may be on the rise [15]. However, a recent systematic review of studies on high risk postoperative Asian patients suggest the rates of significant VTE to be in the order of $2 \%$ [16]. In support of this are observational studies on non-surgical patients. For instance, a similar acute general hospital in the region described a $0.45 \%$ prevalence of DVT in their general patient population [15]. To further confuse the discussion, some studies reported only symptomatic or proximal DVTs whilst others reported on all DVTs including those which arise from deep veins below the knee. The latter are more prevalent but may be of little clinical consequence.

Data on VTE incidence specifically in Asian trauma patients are even scarcer. To our knowledge, the only other study on this was a recent retrospective study from Singapore General Hospital [17]. Whilst they concluded that the incidence of symptomatic VTE is no lower than in the West, the actual incidence of VTE was found to be $0.39 \%$. This is comparable to our results, although it is unclear what proportion of patients in the former study had chemoprophylaxis. Important points to note about that study include the inclusion of minor traumas (the majority of their study group had ISS scores < 9), and likely significant patient heterogeneity (the inclusion criteria varied amongst three time periods during the study).

The major weakness of this present study is its retrospective nature and the fact that the data was derived from a clinical environment where VTE is assumed to be uncommon. With lower clinical vigilance, our VTE incidence probably underestimates the true incidence of VTE in this population. However, our findings are consistent with those in the literature. Secondly, trauma patients are a heterogeneous group of patients which vary in their VTE risk, although we tried to ameliorate this by limiting inclusion to patients with ISS $\geq 9$ who were admitted for $>2$ days.

In summary, we have found that the incidence of VTE is low $(<1 \%)$ in Asian patients who were admitted after major trauma at our institution, which is consistent with the available literature. A fair interpretation of the available literature is that VTE rates in Asians are lower than Caucasians but are not rare. However, as VTE rates of non-chemoprophylaxis patients compare favourably to Western patients who have chemoprophylaxis, doubts exist regarding the need for routine chemoprophylaxis. At our institution, it is not usual practice to institute routine prophylactic chemoprophylaxis with LMWH for trauma patients. However, mechanical prophylaxis and early mobilisation strategies are routinely employed. We employ chemoprophylaxis selectively based upon VTE risk and risk of bleeding.

\section{Conclusion}

The incidence of VTE in the Asian trauma patient appears to be low despite the lack of routine LMWH chemoprophylaxis. Mechanical prophylaxis appears to be sufficient in the prevention of VTE, although pharmacological prophylaxis may be considered in high risk cases.

\section{References}

1. Barrera LM, Perel P, Ker K, Cirocchi R, Farinella E, et al. (2013) Thromboprophylaxis for trauma patients. Cochrane Database Syst Rev 3: CD008303.

2. Datta I, Ball CG, Rudmik L, Hameed SM, Kortbeek JB (2010) Complications related to deep venous thrombosis prophylaxis in trauma: A systematic review of the literature. J Trauma Manag Outcomes 4: 1.

3. Geerts WH, Pineo GF, Heit JA, Bergqvist D, Lassen MR, et al. (2004) Prevention of venous thromboembolism: The seventh ACCP conference on antithrombotic and thrombolytic therapy. Chest 126: S338-S400.

4. Cheuk BL, Cheung GC, Cheng SW (2004) Epidemiology of venous thromboembolism in a Chinese population. $\mathrm{Br} \mathrm{J}$ Surg 91: 424-428.

5. Liew NC, Moissinac K, Gul Y (2003) Postoperative venous thromboembolism in Asia: A critical appraisal of its incidence. Asian J Surg 26: 154-158.

6. Dhillon KS, Askander A, Doraismay S (1996) Postoperative deep-vein thrombosis in Asian patients is not a rarity: $A$ prospective study of 88 patients with no prophylaxis. J Bone Joint Surg Br 78: 427-430.

7. Tun M, Shuaib IL, Muhamad M, Mat Sain AH, Ressang AS (2004) The incidence of post-operative deep vein thrombosis in general surgical patients of hospital universiti sains Malaysia. Malays J Med Sci 11: 75-80.

8. Lee L, Liew NC, Gee T (2012) A survey of contemporary opinions and practices of surgical and intensive care specialists towards peri-operative venous thromboembolism prophylaxis in Asia. Int Angiol 31: 526-533. 
9. Rogers FB, Cipolle MD, Velmahos G, Rozycki G, Luchette FA (2002) Practice management guidelines for the prevention of venous thromboembolism in trauma patients: The EAST practice management guidelines work group. $J$ Trauma 53: 142-164.

10. Bandle J, Shackford SR, Kahl JE, Sise CB, Calvo RY, et al. (2013) The value of lower-extremity duplex surveillance to detect deep vein thrombosis in trauma patients. J Trauma Acute Care Surg 74: 575-580.

11. Selby R, Geerts W, Ofosu FA, Craven S, Dewar L, et al. (2009) Hypercoagulability after trauma: Hemostatic changes and relationship to venous thromboembolism. Thromb Res 124: 281-287.

12. Bahl V, Hu HM, Henke PK, Wakefield TW, Campbell DA Jr, et al. (2010) A validation study of a retrospective venous thromboembolism risk scoring method. Ann Surg 251: 344350.

13. Gould MK, Garcia DA, Wren SM, Karanicolas PJ, Arcelus $\mathrm{JI}$, et al. (2012) Prevention of VTE in nonorthopedic surgical patients: Antithrombotic therapy and prevention of thrombosis, 9th ed: American college of chest physicians evidence-based clinical practice guidelines. Chest 141: e227S-e277S.

14. Lee TH, Alonzo BJ, Differding J, Underwood SJ, Hamilton $G$, et al. (2013) The effects of location and low-molecularweight heparin administration on deep vein thrombosis outcomes in trauma patients. J Trauma Acute Care Surg 74: $476-481$

15. $\mathrm{Ng} \mathrm{HJ}$, Lee LH (2009) Trends in prevalence of deep venous thrombosis among hospitalised patients in an Asian institution. Thromb Haemost 101: 1095-1099.

16. Yeo DX, Junnarkar S, Balasubramaniam S, Tan YP, Low JK, et al. (2015) Incidence of venous thromboembolism and its pharmacological prophylaxis in Asian general surgery patients: A systematic review. World J Surg 39: 150-157.

17. Wong TH, Koh MP, Ng J (2013) Symptomatic venous thromboembolism in Asian major trauma patients: Incidence, presentation and risk factors. Eur J Trauma Emerg Surg 39: 495-500. 